\title{
PROBLEMATIEK VAN STUDENTWERWING IN VERPLEGING
}

\section{REFERAAT GELEWER BY DIE SIMPOSIUM DIE VERPLEEGSTUDENT - QUO VADIS AANGEBIED DEUR DIE DEPARTEMENT VERPLEEGKUNDE, UPE, 1981}

\section{HÉDI VAN WYK \\ Hoofverplegingsbeampte, Transvaalse Departement van Hospitaaldienste}

\section{SUMMARY}

\begin{abstract}
The current manpower shortage has greatly influenced recruitment to the nursing profession. A related issue is the movement of student and qualified nurses out of the profession.

Various problem areas have been identified and to improve recruitment it is imperative that:

- recruitment methods be improved;

- staffing policy be changed so that the student nurse is not regarded mainly as a worker;

- that the status of clinical nursing, especially the status of the ward sister, be reinstated;

- that more guidance and support be provided for student nurses;

- that the socio-economic status of the nurse receive urgent attention.

Furthermore, every nurse has an important role in recruitment and in building the image of nursing by always pro. jecting a positive attitude towards her profession.
\end{abstract}

\section{INLEIDING}

Mannekragtekort is 'n algemene verskynsel van ons tyd en soos ons almal weet, kom dit feitlik in alle sektore van dienslewering voor.

Dit is ' $n$ verskynsel wat volgens kenners voorkom wanneer ' $n$ land in ' $n$ voorspoedfase in sy ekonomiese groei verkeer.

Die wesenlike implikasies van hierdie verskynsel van algemene mannekragtekort wanneer daar 'n eskalasie op die gebied van die handel, nywerheid en ekonomie is, is, ironies genoeg, dat dit dan die menswetenskaplike professies en dienste, onder andere verpleegkunde en onderwys is, wat die eerste en ook die swaarste getref word.

Die teikengroepe vir werwing vir die menswetenskaplike dienste en dié vir die handel en nywerheid en materialistiese dienste is dieselfde, maar die middele tot bedinging vir personeel is tot voordeel van die materialistiese dienste.

Verpleegkundige personeel vloei weg van die menswetenskaplike dienste na die materialistiese dienste en laat hierdie diens mank gaan aan 'n tekort aan personeel.

U sal saamstem dat hierdie wisseling van personeel nie bevorderlik is vir verpleegkunde in die land nie, want geen diens kan groei en hoogtes bereik indien dit van tyd tot tyd mank gaan aan 'n tekort aan die nodige en hoogs opgeleide personeel nie.

Hierdie wipplankryprobleem en die huidige onstuitbare wegvloei van personeel is ' $n$ groot bron van kommer.

\section{BEGRIPPE}

Alvorens die problematiek van werwing bespreek word, is daar 'n paar begrippe wat gedefinieer moet word - begrippe wat verband hou met werwing en die hulpmiddels en tegnieke wat aangewend word.

Reklame: word omskryf as 'n handeling of middel wat ontwerp is om openbare belangstelling te boei; om bepaalde inligting met nuuswaarde uit te reik op 'n wyse waardeur meer openbare aandag/ondersteuning verkry kan word.

Werwing: is die handeling om werkers vir 'n instansie te bekom Die beginsel is BEELDUITBOUING met die oog op werwing.

Advertensie: is die koop van ruimte (koerant/tydskrif) en tyd (in geval van die Radio) om die bemarking van ' $n$ idee, welwillendheid en status te bevorder.

Openbare verhoudings (skakelwerk)Dit word omskryf as doelbewuste, geordende, volgehoue optrede om wedersydse begrip tussen 'n instansie/instelling en die publiek te bewerkstellig en te bevorder. Openbare verhoudings word weer opgedeel in twee, naamlik interne en ekstern:

Interne - ons verhoudings met ons eie mense

Eksterne - ons verhouding met mense buite - met ander woorde die publiek.

Publisiteit Publisiteit is die werktuig van openbare verhoudinge en het die beïnvloeding van die gesindhede en gedragswyse van die publiek ten doel.

Reklame dek ál hierdie begrippe met die doel om kommunikasie te bewerkstellig. 
Eers wanneer daar gekommunikeer word (na binne en na buite), wanneer daar omgang bewerkstellig word, wanneer daar aansluiting, mededeling, wisselwerking plaasvind - eers dan kan daar werklik werwing plaasvind.

\section{KOMMUNIKASIE- (WERWINGS-)} TEGNIEKE EN HULPMIDDELS

Openbare optrede

Persoonlike kontak

Gesindheidspeiling

Films

Radio

TV

Openbare vermaaklikheid

Kommunikasie tussen werkgewer en werknemer

Pers en tydskrifte

Drukwerk

Uitstallings (loopbaan en landbouskoue)

Advertensies

Opleiding

Die bogenoemde is slegs ' $n$ beperkte aantal tegnieke waarmee soos pyle geskiet word na 'n teikengroep, pyle met hakies, sodat wanneer dit tref, dit sal bly vassteek in die teiken en dit nie net sal raak en daarna sal uitval nie

Hierdie tegnieke (pyle) lewer ook elk afsonderlik probleme up en slegs enkele voorbeelde van probleme wat opduik word genoem. Sommige pyle tref byvoorbeeld nie die teiken nie maar skiet verby, ander se hakies is krom, party se punte breek af en sommige bly net nie steek nie - hakies ten spyt.

\section{Persoonlike kontak}

Hoé vertel 'n mens werklik aan iemand (bv 'n skoolkind) hoé dit voel om nagdiens te doen, laat aande te werk of iemand te begelei wat sterf? Elke individu se gewaarwordinge, denke, innerlike belewing, verwerking en vertolking van 'n situasie op gegewe oomblikke is uniek. Geen mens kan werklik vertel en uitdruk hoé dit voel of hoe dit vóel om 'n verpleegkundige te wees nie.

\section{Drukwerk en massakommuni- kasie (media)}

Met uitsondering van enkele van die werwingstegnieke kom dit hoofsaaklik op massakommunikasie neer. $\mathrm{V} \mathrm{d}$ Haag, 'n kenner op die gebied van kommunikasie, het die volgende oor massakommunikasie gesê:

Paper flowers however real they look will never grow en Hyman (ook 'n kenner) raak die kern as hy sê:

One absolute limitation is the Law of Raspberry jam: The wider you spread it the thinner it is.

\section{Advertensie}

Beelduitbouende advertensie kan ook soms die verkeerde uitwerking hê - ter illustrasie kan die klassieke voorbeeld van die advertensie van Melk van Magnesium genoem word. Die vrou het dié wonderlike soort melk geadverteer gesien en besluit dat dit net die regte ding vir haar kind is en dit gegee in plaas van gewone melk, met die gevolg dat, in die plek van 'n gesonde kind soos die advertensie voorspel het, sy net mooi die teenoorgestelde gekry het - 'n maer, sieklike kind.

\section{TEIKENGROEPE}

Voor werwing kan plaasvind en daar besluit kan word watter tegniek of hulpmiddel aangewend gaan word, moet die teikengroep geïdentifiseer word.

Met dié doel is die teikens in drie afsonderlike groepe ingedeel en word elke groep en die problematiek daaraan verbonde kortliks afsonderlik behandel. Die drie groepe is:

Skoolverlaters

Verpleegkundestudente in opleiding

Geregistreerde verpleegkundige

\section{Skoolverlater}

$\mathrm{Na}$ voltooiing van twaalf skooljare is daar sewe wedywerende instansies wat van vroukragte voorsien moet word, naamlik:

Onderwys

Universiteite

Gesondheid

Handel

Nywerheid

Staatsdiens en verwante dienste

Huweliksmark

U kan moontlik u wenkbroue lig oor die huweliksmark maar statistieke het bewys dat daar in 1970 in die Republiek van Suid-Afrika reeds $8,1 \%$ blanke vroue in die ouderdom 15-19 jaar getroud was.

As al bogenoemde instansies hul regmatige deel van die beskikbare St X-/matrikulante moet kry, het statistieke bewys dat elke van die sewe instansies, gedurende 1981 ongeveer 3300 van die potensiële kandidate moes gewerf het.

As gegewens wat vir verpleegkunde in die Transvaal beskikbaar is, as maatstaf geneem word, kom die volgende aan die lig:

$\begin{array}{lrr}\begin{array}{l}\text { Getal St } 10-\text { matrikulante wat } \\ \text { in die gewone kursus slaag }\end{array} & 1979 & 1980 \\ & 1980 & 11610 \\ \begin{array}{l}\text { Hiervan moes verpleegkunde } \\ \text { op die } 1 / 7 \text { formule die vol- }\end{array} & & \\ \text { gende getalle in } 1980 \text { en } 1981 \\ \text { gekry het } \\ \begin{array}{l}\text { In werklikheid hel verpleeg- } \\ \text { kunde in } 1980 \text { en } 1981 \text { slegs die } \\ \text { volgende getalle gekry }\end{array} \\ \begin{array}{l}\text { Dus minder as die regmatige } \\ \text { deel van } 1 / 7 \text { was }\end{array}\end{array}$

Wanneer dié syfers in oënskou geneem word is dit duidelik dat die verpleegkundeberoep in die Transvaal geensins sy regmatige deel studente van die St 10-/matrikulantepotensiaal in die Transvaal gekry het nie.

\section{Problematiek ten opsigte van werwing van skoolverlaters}

Pyle wat die skoolverlater laat wegskiet na ander instansies.

Die houding van ouers van tienderjarige dogters teenoor verpleging as loopbaan speel 'n groot rol. Uit 'n houdingsopname wat onder ouers van hoërskooldogters gedurende April 1980 gemaak is, blyk dit dat $38 \%$ van die totale monster van bykans 800 , beswaar daarteen sou hê indien hul dogters verpleging as loopbaan kies.

Redes vir hulle besware het in volgorde van belangrikheid só daar uitgesien:

- salaris;

- werksure;

- gebrek aan erkennmg van die verpleegkundige as professionele persoon;

- status van die verpleegberoep;

- tipe werk;

- ander redes - gebrek aan voldoende inligting oor verpleging;

- intellektuele vermoëns van dogter te hoog. 
Dit is insiggewend dat $10,5 \%$ van die aantal persone wat besware teen hulle dogters se keuse van verpleging as loopbaan het, self geregistreerde verpleegkundiges was.

Die aanloklikheid van aantrekliker hoër salarisse asook, populêre diensure-tipe werk speel 'n geweldige groot rol, veral by die ekonomies minder gegoede of die labielgemotiveerde skoolverlater wanneer daar op 'n beroep besluit moet word.

Die houding van die onderwyser, beïnvloeding en leiding ten opsigte van beroepskeuse en vakkeuse speel 'n groot rol. Probleme word ondervind om persoonlik met skoliere in aanraking te kom, daar word sterk op die onderwyser geleun om die verpleegkundige se saak in die voorligtingsperiode te stel - persoonlik kan dit volgens regulasies en skoolbeleid nie geredelik gedoen word nie. Dit bring 'n mens terug by die problematiek van massamedia/kommunikasie wat reeds genoem is.

Die beeld van die verpleegkundeberoep, veral ook soos in die openbare pers weerspieël word. Persuitknipsels uit koerante wat oor die hele Republiek van Suid-Afrika verskyn, toon dat $65 \%$ van alle beriggewing in verband met verpleging oor salarisontevredenheid en swak diensvoorwaardes handel.

Motivering en inligting. Daar word nie genoegsame inligting oor die beroep uitgereik nie. Die skolier moet vroegtydig die nodige inligting in verband met verpleging hê om sodoende die regte vakkeuse te maak; dit dien ook as motivering vir studies en loopbaanbeplanning.

\section{Problematiek ten opsigte van die studentverpleegkundige}

Die keuse van verpleging as 'n beroep is ' $n$ belangrike besluit want om verpleegster te wees, behels veel meer as om bloot 'n bevredigende pos te beklee. Dit beteken om déél te word van 'n span, 'n span wat hulle toewy aan dic ıslewering. Verpleging bied jou die geleentheid om mense, wie se lewenswyse. waardes, kulture en oortuigings totaal van jou eie mag verskil, te verstaan, te aanvaar, te vertrou en met jou kennis en persoonlike vermoëns te dien.

Verpleegkunde laat jou ook dinge verstaan - dinge soos jouself, jou eie gesindhede, jou eie moontlikhede en die gevoelens wat jy teenoor jouself en ander koester. Verpleging maak jou diensbaar vir ander, maar bowenal vir God.

Verpleging bied ook punte vir persoonlikheidsgroei en geleenthede om tot ' $n$ beroepspersoon te ontwikkel - daar is verskillende voortgesette studiemoontlikhede wat die geleentheid bied om in verskillende rigtings te spesialiseer, en 'n verskeidenheid werkterreine en mense.

Daar word ervaring opgedoen wat die lewe meer betekenisvol maak - om 'n lewensbelangrike diens aan die mens met gesondheidsbehoeftes te lewer.

Where else can 3 minutes work last a lifetime?

(Opskrif van ' $n$ advertensie in verband met hartarres, en hóe waar is die nie!). Behalwe dat verpleging 'n lewensverrykende beroep is, is dit ook ' $n$ betalende beroep. Die student word vergoed vir haar deel van pasiëntesorg wat sy tydens haar kliniese opleiding in die hospitaal doen - dit maak haar selfonderhoudend. Sy betaal haar losies, klasgeld (in geval van graadstudente), boeke en voorsien self in haar materiële behoeftes.

Verpleging is nie Utopia nie nêrens in ' $\mathrm{n}$ beroep kry 'n mens Utopia nie - daarom het die verpleegberoep dan ook sy stekeltjies .

Die grootste probleem ten opsigte van werwing lê in die behoud van gewerfde studente in die beroep. Die eindtotaal aan verliese of staking van opleiding van 2120 studentverpleegkundiges gedurende 1979 in die Republiek van Suid-Afrika is 'n duidelike aanduiding dat die verpleegkundeberoep geensins voldoende studente behou nie.

Hierdie verliese of staking van opleiding moet hoofsaaklik aan die volgende toegeskryf word:

\section{Die studentverpleegkundige word as werkkrag beskou}

Sodra daar minder studente aangestel word, word dit as 'n onmid- dellike bedreiging vir pasiëntesorg beskou.

Die periodes wat sy as student aan haar studies wy, word as 'n noodsaaklike euwel beskou, en hoe minder studente beskikbaar, hoe erger die druk om klastyd te verminder.

Die reg van die studentverpleegkundige om student te wees in die klaskamer en in die hospitaal-afdeling (kliniese situasie) word misken.

Sy moet werk.

Die leer is sekondêr

Die status, salarisvooruitsigte en werksomstandighede van die suster, soos gesien deur die student, beïnvloed haar besluit om te bly of te staak.

Verpleging voldoen nie aan die verwagtinge van die student nie.

Weer eens kom die status en werksomstandighede van die geregistreerde verpleegkundige en die student in gedrang, asook verwagtinge wat deur werwingsaksies geskep word.

- Studente dra groot verantwoordelikheid maar word as onvolwasse benader.

- Swak interpersoonlike verhoudinge

- Wanindrukke wat oor die beroep deur voorligtingsbeamptes en inligtingsmateriaal geskep word (verwys terug na problematiek ten opsigte van k o m m u n ik a s i t e g n i e k e /hulpmiddels).

- Gebrek aan geheimhouding oor persoonlike sake.

- Die tekort aan poste en bekleërs ten opsigte van geregistreerde verpleegkundiges ontneem die student die noodsaaklike begeleiding deur susters.

- Die getalleverhouding van susters, studente, verpleegassistente en dosente op opleidingskole se diensstaat veroorsaak dat daar te veel studente vir die getal opgeleide personeel is - weer eens onvoldoende ondersteuning en nie genoeg begeleiding nie.

- Afronding van die student as suster Die opleiding van die student is toegespits op die slaag in eksamens en die afronding van 
die student tot suster en as mens lei skipbreuk.

Nagdiens wat ontwrigtend is en 'n onnatuurlike leefwyse vir onredelike lang en aaneenlopende tye meebring, onvoldoende personeeltoekenning, te hoë eise en te gou, te hoë werklading, onvoldoende leiding aan die student, wat lei tot liggaamlike en geestelike uitputting kan dit as uitdaging dien vir die student wat graag self besluite wil neem en verantwoordelik wil optree? Sy moet voel dat sy vertrou word.

\section{Student-dosentverhouding}

Die kollegedosente is geografies verwyder van die studente in die hospitaal, terwyl die dosente by die hospitaal te min is, wat weer eens op onvoldoende begeleiding en ondersteuning dui. Sinvolle toepassing van die teorie in die praktyk ontbreek en die vraag kan gestel word in watter mate die student vandag uitgelewer is aan haar eie onkunde en probeer-en-trefleer.

\section{Die rolmodel (Identifikasie)}

Die vraag kan gestel word: met wie identifiseer die student haar? Die suster, van wie sy, soos later sal blyk 'n negatiewe beeld het? Die matrone? Die dosent?

Aanloklikheid van hoër salarisse, aantrekliker byvoordele, gereelde diensure en dergelike meer speel 'n geweldige rol by studente, veral by die ekonomies minder gegoede of die labiel-gemotiveerdes wanneer hulle ' $n$ besluit moet neem tussen of met hul opleiding aangaan ò ' $n$ goed besoldigde werk neem. Daarbenewens is dit juis die akademies sterk student vir wie daar elders die grootste aanvraag is.

\section{Problematiek - geregistreerde verpleegkundige}

Vandag nog student - môre Suster!

So betree die verpleegkundige die volgende fase. Vir haar is dit nie alleen 'n voorwaartse beweging in haar beroep nie maar ook in haar persoonlike lewe. Heel moontlik volg die huwelik wat vele aanpassings van haar kant verg.

Sy het 'n verantwoordelikheid teenoor alle mense - haar pasiënte, haar studente, haar saalpersoneel, die ander lede van die gesondheidspan, die matrone, die owerheid. Sy is bestuurder maar terselfdertyd ook arbeider (werkkrag).

Sy laat die spel van die kantlyn af voortgaan, druk self 'n skrum en sien toe dat dit haaks is. Sy neem leiding maar aanvaar ook leiding. Sy verduur onverwagte krisissituasies en hanteer dit, maar as gevolg van die feit dat daar nie voldoende studentverpleegkundiges na vore kom om as professionele verpleegkundiges opgelei en voorberei te word nie, bring dit mee dat daar minder geregistreerde verpleegkundiges is om die nodige dienste te lewer, terwyl die aanvraag na hierdie dienste groot is en steeds toeneem.

Dit bring dan ook mee dat die klein aantal getroue en toegewyde verpleegkundiges wat behou word, nou soveel meer moet doen om die uiters noodsaaklike en lewensbelangrike dienste aan die gemeenskap te lewer.

\section{Die negatiewe beeld van die saalsus-} ter

Die saalsuster word (deur studentverpleegkundiges) om verskeie redes as 'n persoon sonder status beskou.

- Haar salaris vergeleke met haar verantwoordelikhede is ontoereikend.

- Omdat die saalsuster oor die algemeen jonk is en gebrek het aan ervaring, dwing sy nie haar gesag as persoon-in-beheer van haar saal af nie. Sy word ook deur niemand bygestaan nie.

- Die sonematrone doen afbreuk aan die saalsuster se posisie - só ook die kliniese dosent — albei hierdie persone beklee meer senior range as sy en het vrye toegang tot die saal.

- Die ander lede van die terapeutiese span kom en gaan soos dit hulle pas - selde soos dit die saalsuster en haar saal se werksaamhede pas - sy het dus hieroor geen gesag nie.

- Gebrek aan vertroue in haar en erkenning as professionele spanlid deur die ander spanlede en die publiek.
- Die saalsuster se posisie word ook verder verswak deurdat sy die produk is van 'n gebrekkige opleidingstelsel.

- Die feit dat sy bereid is om saalsuster te bly, word deur baie studente vertolk as 'n gebrek aan ambisie eerder as aan toegewydheid.

Sy word deur die studente gesien as 'n oorwerkte persoon met swak verhoudinge en geen sosiale lewe nie; sy doen nie basiese verpleegsorg nie en omdat sy nie verpleeg nie, stagneer sy klinies en is nie in staat om die student op te lei nie. Sy word beskou as 'n kantoorwerker wat nie tyd het om by die pasiënt of student uit te kom nie. Bogenoemde faktore lei daartoe dat haar gesindheid vertolk word as negatief teenoor haar taak, as verpleegkundige wat nie bereid is om by pasiëntesorg en leiding aan die student betrokke te raak nie.

\section{Erkenning van die verpleegberoep}

Dit lei geen twyfel dat daar diskriminasie teen die verpleegberoep bestaan nie - 'n sterk demotiveringsfaktor is byvoorbeeld besoldiging.

\section{Amptelike werksweek}

Daar heers ongelukkigheid omdat die 40-uurwerksweek nog nie amptelik vir verpleegkundiges neergelê is nie - veral ten opsigte van oortyd en vergoeding daarvoor.

\section{Vervoer}

Ongereelde diensure bring mee dat personeel nie altyd van openbare vervoer gebruik kan maak nie. Dit noodsaak personeel om van privaat motorvervoer gebruik te maak, wat van die duurste soort vervoer is.

\section{Behuising en huisvesting (spreek vanself)}

Erkenning van grade (Universiteit)

Daar is geen erkenning van verpleegkundegrade nie - slegs erkenning van registreerbare kwalifikasies, maar 'n nie-verplegingsgraad wat toepaslik is, bv BA(Sosiale Wetenskappe) word volgens RWK erken. 
Hulpdienste aan verpleegdienste

Daar is 'n gebrek aan poste, bekleërs, opleiding en leefbare salarisse by personeel wat ondersteunende diens lewer.

\section{Diensvoorwaardes}

Dit is van die moeilikste inligting om te bekom: by voornemende toetreders is dit nogal belangrik. Personeel dra ook nie kennis van eie diensvoorwaardes nie.

\section{Naskoolsentrums}

Terwyl daar vrylik crèche-fasiliteite voorsien word. word daar nie genoeg voorsiening in die gemeenskap vir die skoolgaande kinders van werkende moeders gemaak nie.

By hospitale word slegs voorsiening gemaak vir kinders tot 10 jaar - daar eindig dit

\section{Beroepstrots}

As gevolg van al bogenoemde faktore ontbreek die trots om in verpleegkundige te wees.

\section{AANBEVELINGS}

\section{Ten opsigte van skoolverla- ters}

Die ontoeganklikheid van hoërskole vir werwingsbeamptes vir die bekendstelling van die verpleegberoep moet reggestel word.

- Vertoë moet aan die Direkteur van Onderwys gerig word.

- Die voorligtingsonderwysers en ouers moet beter ingelig word.

- Die kind moet reeds van vróeg af, hoe jonger hoe beter, oor die verpleegberoep ingelig word.

- Inligting omtrent die regte vakkeuse vir die beroep moet dringend aandag geniet.

- 'n Nasionale werwingsveldtog moet op tou gesit word.

- Navrae moet sinvol en reg hanteer en opgevolg word.

\section{Ten opsigte van studentver- pleegkundige en geregis- treerde verpleegkundige}

Verandering van die personeelvoorsieningsbeleid in verpleegdienste in opleidingshospitale is noodsaaklik

Die probleem in sy totaliteit wentel om die status van die student hoofsaaklik as leweraar van pasiëntesorg.

Die volgende moet reggestel word:

die studentverpleegkundige moet in die saalspan ingesluit word, maar só dat daar nié uitsluitlik of hoofsaaklik op die student vir pasiëntesorg gesteun moet word nie.

Die status van kliniese verpleging Dit móet in ere herstel word, terwyl dié van administratiewe verpleegtake in perspektief gebring moet word.

- Die status van die saalsuster as bestuurder van haar saal moet verskans word. Faktore wat die status van die saalsuster beïnvloed moet geïdentifiseer en reggestel word sodat die student haar wel weer met die saalsuster kan identifiseer.

- Die verpligtinge van die saalsuster met betrekking tot die opleiding en ondersteuning van die studentverpleegkundige moet by haar tuisgebring word.

- 'n Beleid van beter benutting van kliniese onderrigpersoneel in die leiding en ondersteuning van die student moet gevind word.

\section{Opleiding van studentverpleegkun- diges}

Met die oog op die probleme wat die student as gevolg van 'n gebrek aan leiding en ondersteuning ondervind. moet dit aan die student verleen word by wyse van:

- moontlik "n voogdosentestelsel in die kollege. met opvolging deur die kollegedosent in die hospitaal;

- 'n studentediensburo of soortgelyke diens by opleidingshospitaal;

- opknapping van die kliniese verpleegkennis van die dosent by die kollege - 'n oplossing moet gevind word om dit vir haar moontlik te maak om op die hoogte van die vak verpleegkunde te kom en te bly, sodat sy die nodige ondersteuning en leiding aan die student kan gee;

- die aanstelling van slegs verpleegkundiges met toepaslike ervaring as dosente.

Met die oog op die oorlading van leerplanne en eksamengerigte onderrig wat direk in stryd is met die doelstelling van die S.A. Raad op Verpleging, moet dringende aandag aan die eksamenstelsel en ander maatreëls gegee word.

Gesien die klagtes oor vaagheid van opleidingsdirektiewe en ontoepaslikheid van sekere vakke, moet hierdie aspekte in heroorweging geneem word.

Weens die bevinding dat studentverpleegkundiges tydens die onnodige lang tydperke van nagdiens onvoldoende toesig en leiding ontvang - wat noodwendig afbreuk moet doen aan die kwaliteit van die opleiding - moet die instel van maksimum vereistes in heroorweging geneem word.

Die Sosio-ekonomiese status van die verpleegkundige moet dringend reggestel word.

\section{SLOTOPMERKING}

Die wa het tot hiertoe drie wiele gehad

skoolverlater,

studenteverpleegkundige, geregistreerde verpleegkundige, maar met slegs drie wiele kan verpleging nie voorwaarts nie en daarom moet daar 'n vierde wiel aangesit word. Sonder dié wiel sal dié swaargelaaide wa nooit deur die drif kom nie - die SELF.

Die hand moet in eie boesem gesteek en selfondersoek toegepas word.

Vra uself af: wat doen ek om verpleegkunde te bevorder, wat doen ek ten opsigte van werwing, beeldbouing, wat is my houding jeens my beroep - 'n beroep wat uself gekies het? Is u trots daarop?

Poog $u$ om deur $u$ handel en wandel mense na die verpleegberoep te trek?

Is $\mathbf{u}$ positief?

'n Positiewe gesindheid by verpleegkundiges is nie net vir die opbou van die verpleegmag belangrik nie, maar ook vir suksesvolle werwing.

Wie weet dalk loop ons die volgende eersdaags in die pers raak:

It will interest nurses who think of seeking work abroad to learn that the supply of nurses in the (Transvaal) Republic of South Africa is much too great for the demand. (Nursing Times, 6 Mei 1905) Verpleging Quo Vadis. 